Научная статья

УДК 591.526(571.54)

DOI 10.18101/2587-7148-2021-1-30-41

\title{
ОРГАНИЗАЦИЯ УЧЕТА БОЛЬШОГО БАКЛАНА БАЙКАЛЬСКОЙ ГРУППИРОВКИ
}

\author{
Г. А. Янкус, М. Е. Овдин, А. А. Ананин
}

(C) Янкус Геннадий Андреевич

научный сотрудник, ФГБУ «Заповедное Подлеморье»

Россия, 671623, Республика Бурятия, пос. Усть-Баргузин, ул. Ленина, 71

jankus@rambler.ru

(C) Овдин Михаил Евгеньевич

директор ФГБУ «Заповедное Подлеморье»

Россия, 671623, Республика Бурятия, пос. Усть-Баргузин, ул. Ленина, 71

znp.ovdin@mail.ru

\section{(C) Ананин Александр Афанасьевич}

доктор биологических наук, заместитель директора по НИР,

ФГБУ «Заповедное Подлеморье»

Россия, 671623, Республика Бурятия, пос. Усть-Баргузин, ул. Ленина, 71

главный научный сотрудник,

Институт общей и экспериментальной биологии СО РАН

Россия, 670047, Улан-Удэ, ул. Сахьяновой, 6

a_ananin@mail.ru

Аннотация. В работе представлены методика учета численности и особенности экологии птиц, которые необходимо учитывать при организации долговременного мониторинга байкальской группировки большого баклана. Учет численности и распределения большого баклана предваряют социологические опросы и анкетирование населения в зимний период. С учетом собранной информации разрабатывается план полевых исследований, а с прилетом птиц начинаются прямые подсчеты гнездящихся, кормящихся и отдыхающих особей на тех или иных территориях бассейна оз. Байкал, сопровождающиеся картированием. При этом первоочередное внимание уделяется наиболее крупным колониям. Применение фото-, видеорегистраторов и камер, беспилотных летательных аппаратов и быстроходных судов позволяет в короткие сроки и качественно выполнить учет. Данная методика апробирована в 2013-2020 гг. в Северо-Восточном Прибайкалье, включая территорию Чивыркуйского залива (Забайкальский национальный парк), долину p. Верхняя Ангара (с Верхнеангарским сором) и северо-восточное побережье оз. Байкал (Баргузинский государственный природный биосферный заповедник им. К. А. Забелина и Фролихинский государственный природный заказник).

Ключевые слова: большой баклан; учеты численности; озеро Байкал.

\section{Для цитирования:}

Янкус Г.Н., Овдин М.Е., Ананин А.А. Организация учета большого баклана байкальской группировки // Вестник Бурятского государственного университета. Биология. География. 2021. № 1. C. 30-41. DOI 10.18101/2587-7148-2021-1-30-41 
Г.Н. Янкус, М.Е. Овдин, А.А. Ананин. Организация учета большого баклана байкальской группировки

В начале двадцать первого века, после полувекового отсутствия, большой баклан (Phalacrocorax carbo sinensis) вновь появился в бассейне озера Байкал в своих традиционных местах обитания $[5 ; 8-11 ; 14]$. Этот вид не только снова начал встречаться на Байкале, но его распространение и численность продолжают быстро расти. Большой баклан - типичный ихтиофаг, он играет существенную роль в экосистеме Байкала. Потребовалось выполнение долговременных наблюдений за изменениями его численности и распределением по местообитаниям [1-3; 6; 7].

Организация долговременного мониторинга территориальной группировки большого баклана невозможна без разработки и апробации методики учета его численности и популяционных особенностей [15]. Такие исследования выполнены в Северо-Восточном Прибайкалье, включая территорию Чивыркуйского залива (Забайкальский национальный парк), долину р. Верхняя Ангара (с Верхнеангарским сором) и северо-восточное побережье оз. Байкал (Баргузинский государственный природный биосферный заповедник им. К. А. Забелина и Фролихинский государственный природный заказник) в 2013-2020 гг.

Территориальная группировка большого баклана, обитающая в бассейне озера Байкал, обладает рядом свойств, отличающих ее от характеристик многих других внутривидовых группировок. Эти отличия определяются особенностями занимаемой видом экологической ниши, обозначающей и устанавливающей место вида в сообществе. Особенности байкальского населения большого баклана определяются абиотическими и биотическими условиями мест обитания его различных возрастных групп, прежде всего стациями размножения, питания, переживания неблагоприятных условий [6;7].

В то же время условия обитания отдельных группировок этих птиц в регионе также многообразны, что сказывается на экологических, демографических, поведенческих особенностях групп внутри населения вида на оз. Байкал. Эти особенности включают возраст половой зрелости, продолжительность жизни, демографическую структуру группировок, суточную и сезонную подвижность и распределение по стациям, спектры питания, отличия в дистанции вспугивания и поведенческих реакциях на присутствие людей, что наряду с иными факторами определяет условия организации и проведения учетных работ.

Поскольку учетные работы могут выполняться разными группами учетчиков и специалистов, необходимо достичь единообразия и достаточного уровня достоверности, в том числе путем определения единых терминов, методов классификации и характеристики биотопов и т. д.

Терминология, применяемая при проведении учетных работ по оценке населения большого баклана на Байкале и используемая при ведении документации.

Численность - суммарное или общее количество особей на определенной территории (бассейн реки, акватория залива, группа водоемов и т.п.).

Абсолютная численность - число особей (пар) в колонии, в местах концентрации в конкретной местности.

Относительная численность - количество особей, выраженное в показателях встречаемости за единицу времени, на единицу протяженности маршрута. 
Примеры:

- с 5 до 10 ч утра 15 июля мимо точки А на север пролетело около 80 бакланов;

- на маршруте от точки А до точки Б 15 июля с 14 до 18 ч (протяженность 12 км) учтено 70 особей, в т. ч. 10 - на воде, 25 - на кустах и камнях и 35 - в полете.

В данном случае последующий пересчет будет выполнять специалист, обрабатывающий карточку.

Плотность группировки, обилие - среднее число особей птиц, рассчитанное на единицу площади (на 1000 га площади акватории, используемой видом в качестве кормовых участков, а также участков суши в местах гнездований и концентраций в периоды ночевок и отдыха). Рассчитывается по формуле:

$\mathrm{P}=(\mathrm{Na}+\mathrm{N} \sigma) /(\mathrm{Sa}+\mathrm{S} \sigma)$, где

$\mathrm{P}$ — плотность, Na - численность птиц на площади кормовых акваторий; Nб численность птиц на участках гнездовий и концентраций; $\mathrm{Sa}$ - площадь кормовых акваторий (в тыс. га), Sб — площадь участков гнездовий и концентраций (в тыс. га).

Население птиц. Много, средне, мало (глазомерная оценка, в том числе по следам пребывания).

Определяется наличие врагов (чайки, лисицы) и иных животных в биотопе.

Кормовые условия для большого баклана. По возможности характеризуются кормовые условия водоема по периодам и приоритетности кормов.

Пример. На кормовых участках много нерестящегося ельца в июне. В сентябре баклан следует за нерестовым омулем и т.п. или в водоемах обитает в основном, окунь (малочислен, многочислен).

Антропогенный фактор. На обследованной территории примерное (данные охотнадзора и опросные) количество добываемых охотниками бакланов весной и осенью (отдельно). Количество преднамеренно уничтожаемых гнезд и птиц (примерно).

Динамика численности. Личные наблюдения учетчика и данные опроса о дате первого появления бакланов (год) на участке учета и примерная динамика изменения численности и расселения по годам.

Участок гнездования. Место (участок, территория), на котором находятся гнезда, обитаемые в сезон учета. Поскольку в ряде случаев через 2-3 года бакланы могут изменять участки гнездования, то покинутые участки не учитываются, а делается примечание в анкете.

Типы гнездования:

a) Скальный - на карнизах береговых и островных скал.

b) Наземный - гнезда сооружаются на земле из сучьев и толстых стеблей трав и скрепляется пометом (их высота 40 см и более).

с) Лесокроновыц - на деревьях (береза, ива, лиственница и т. д.) и кустарниках.

d) Тростниковый - на заломах тростника и камышей.

е) Смешанный - колония состоит из субколоний с разным типом гнездования, например, часть гнезд на скалах, а часть на деревьях.

Стация. При оформлении материалов учетных работ для единообразия предлагается использовать термин «стация», определяющий совокупность всех воздействующих на группировку внешних условий, внешне проявляющийся как обладающий определенными свойствами участок физического пространства, занимаемый этой 
Г.Н. Янкус, М.Е. Овдин, А.А. Ананин. Организация учета большого баклана байкальской группировки

группировкой. Следовательно, употребительны конкретные термины (стация питания, размножения, концентраций).

Во избежание неоправданного усложнения методики учета большого баклана в бассейне Байкала, но с обеспечением необходимого уровня достоверности, предлагается использовать следующие категории.

А. Стации питания:

- байкальская акваториальная (заливы, губы, бухты и открытая акватория водоема);

- речная пойменная (реки, протоки и не отшнурованные в половодье озера);

- озерная (изолированные от рек озера с автономной ихтиофауной).

Б. Стации размножения:

- островные (острова, как правило, скалистые, с отсутствием крупных хищников - лисица, волк и т.д., береговые, чаще доступные только для птиц, утесы);

- пойменные (поймы рек и иных водоемов).

Участки гнездования - скальный, наземный, лесокроновый, тростниковый, смешанный.

В. Стации концентраций - совокупность внешних условий и участков в периоды дневного и ночного отдыха бакланов, а также перелетов за пределами стаций размножения и питания.

\section{Методы учета}

Получению информации о численности и распределении байкальской группировки большого баклана путем прямых подсчетов гнездящихся, кормящихся и отдыхающих особей на тех или иных территориях бассейна оз. Байкал должны предшествовать социологические методы исследований в форме опросов и анкетирования, благодаря которым к получению первичных данных удается привлечь широкие массы неспециалистов. Анкетирование и опросы следует проводить как среди лиц, профессионально связанных с живой природой (работники лесного и охотничьего хозяйства), так и среди любителей и знатоков природы (краеведы, охотники) [4].

Сбор опросных данных о распространении и численности бакланов следует осуществлять в зимнее время или одновременно с полевыми исследованиями по методике, предложенной для получения информации о редких видах в рамках программы «Фауна» студенческих дружин по охране природы [13]. Базовое преимущество устного опроса - возможность оценить достоверность получаемой информации и уточнить на месте любые детали. Основной недостаток этого метода - значительная трудоемкость.

Анкетирование - существенно менее трудоемкий (хотя одновременно и менее эффективный) метод. Процент возврата заполненных анкет обычно низок. Часто очень сложно оценить достоверность содержащихся в анкете сведений, кроме того, небрежно заполненная анкета требует дополнительных усилий по устранению пробелов в информации. Процент возврата заполненных анкет может быть значительно повышен, если вместе с анкетой респондент получает конверт с адресом для отправки своих материалов. При организации анкетирования целесообразно использовать системы служебных рассылок регионального управления Росприроднадзора, лесного агентства, службы охотничьего хозяйства. 
С учетом собранной информации разрабатывается план полевых исследований. Такими обследованиями с участием профессионалов необходимо охватить максимально возможную часть территории бассейна оз. Байкал с выявленными местами обитания большого баклана. Первоочередное внимание следует уделить наиболее крупным колониям, в которых сосредоточена значительная доля гнездящихся в регионе птиц.

Учеты байкальской группировки большого баклана проводятся несколькими способами.

1. Сплошной метод учета путем абсолютного пересчета обитаемых гнезд в колонии. Целью абсолютного учета является определение точной численности всех птиц, находящихся на определенной территории (акватории), для получения объективной оценки. Эти цифры не предполагают никакой дополнительной статистической обработки и не должны соответствовать каким-либо предполагаемым значениям. Достоверный учет основан на предположении, что все держащиеся на какой-либо территории птицы могут быть выявлены. Сплошной метод учета используется при полном подсчете гнездящихся, размножающихся пар (обитаемых гнезд) в колонии, всех птиц в местах коллективных ночевок и концентраций (преимущественно неполовозрелых особей), бакланов всех возрастных групп в стациях питания. Гнездовые колонии обычно подвергаются сплошному пересчету. Если колония расположена на деревьях, то обследованные деревья во избежание повторного учета метятся мелом. При проведении учетов гнездящихся больших бакланов на скалистых берегах и утесах помимо прямого подсчета применяется фотосъемка крупных колоний с последующим вычислением количества гнездовых пар.

2. При невозможности выполнить сплошной учет на всей площади колонии или на территории обитания баклана учетчики используют метод пробной площади: выявление мест с различной плотностью гнездования, выбор в таких местах пробных площадок, пересчет гнезд на площадках и последующая экстраполяция на всю площадь, занятую колонией, или метод трансекты: подсчет гнезд или взрослых птиц на учетных площадках, расположенных в линейном порядке.

3. В тех ситуациях, когда выявить точное местонахождение колонии и определить численность птиц в ней, по тем или иным причинам затруднительно, возможно использование результатов наблюдений за кормовыми миграциями птиц. Примерное местонахождение колонии определяется по направлениям миграций, а размер колонии - по числу птиц, совершающих кормовые перемещения.

Данные учета в каждой обследованной колонии должны сопровождаться информацией о размещении колонии, наименовании и происхождении водоема, на котором она располагается, характеристике растительности, фенологическом состоянии колонии в момент обследования, занимаемой ею площади, численности гнездящихся птиц, основных местах кормежки птиц. Количество гнездящихся птиц определяется путем подсчета заселенных гнезд. Каждое гнездо соответствует одной паре взрослых птиц. Одновременно с подсчетом заселенных гнезд проводится сбор информации о количестве птенцов, а при раннем учете - количестве яиц в гнездах большого баклана для последующего определения средней величины количества птенцов в колонии. 
Г.Н. Янкус, М.Е. Овдин, А.А. Ананин. Организация учета большого баклана байкальской группировки

Результаты учетных работ на отдельных территориях заносятся в предлагаемую форму регистрации сведений:

Приложение A

Карточка учета численности большого баклана байкальской группировки

1. Группировка

(чивыркуйская, баргузинская, маломорская, северобайкальская, селенгинская)

2. Субгруппировка

(местность регистрации концентраций, № на схеме)

3. Дата выполнения наблюдений

4. Время: с __ час. до __ час., перерывы

5. Точки или маршруты наблюдений

(обозначить заглавными буквами, указывать местность, данные навигатора)

6. Стация

(питания, размножения, концентраций, учет на маршруте суточных или транзитных

перелетов). Краткая характеристика стации (скалы, тип водоема и местности и т.п.)

7. Метод учета

8. Тип участка гнездования

(выборочный, сплошной)

9. Площадь обследованного участка в пределах видимости и обнаружения объектов учета (примерно) и (или) протяженность маршрутов перемещения учетчиков

10. Кормовые условия, объекты питания

11. Факторы воздействия на группировку

(хищники, охотники и т.п.)

12. Количество особей на каждой стации

13. В группировке (субгруппировке) учтено особей баклана, в том числе половозрелых , неполовозрелых

(в зависимости от периода года и возможности отличить эти группы птиц)

Количество гнезд

Краткое описание места гнездования

Данные GPS-навигатора Тип участка

14. Воздействие баклана на экосистемы

15. Приложение (в электронном виде или на бумажном носителе):

- схема обследованного участка на лист.

— фото и видеоматериалы (перечень, количество)

— данные навигаторов в электронном виде или на бумажном носителе. 
Учетные работы выполнены:

Ст. группы

(Ф.И.О. полностью, № тел.)

Учетчики

"__ " 20 $\Gamma$.

Обработка учетных материалов и оформление отчета о результатах учета численности большого баклана выполняется ответственным за учетные работы координатором таких работ:

Приложение Б Утверждаю

(руководитель ООПТ, регионального ведомства или охотпользователь)

Информационный отчет о выполнении работ по учету численности большого баклана на территории

Учетные работы выполнены на байкальской группировки.

(административный район, водоем, бассейн, ООПТ, охотхозяйство и т.п.) Даты начала и окончания полевых работ

Работы выполнены с применением

(транспортные средства водные, наземные, воздушные суда, беспилотники, фото- и

В результате аналитической обработки данных полевых учетных работ и иной информации установлено:

На исследуемой (указанной) территории учтено обитаемых гнезд большого баклана.

На стациях размножения учтено особей всего:

(название стации и № на схеме, количество особей)

На стациях питания

На стациях концентраций

(местность и № на схеме)

(местность и № на схеме)

С допустимым процентом погрешности считаем, что численность большого баклана группировки всего 
Г.Н. Янкус, М.Е. Овдин, А. А. Ананин. Организация учета большого баклана байкальской группировки

особей, в том числе неполовозрелых и не гнездящихся

Основными объектами питания баклана являются

(виды рыб)

Сдерживающие и благоприятные для вида факторы воздействия на группировку

Количество добываемых охотниками (уничтожаемых) птиц за сезон Оценка воздействия большого баклана на рыб и окружающую среду:

особей.

Динамика численности по годам (относительно):

Оценка состояния группировки, роль вида в экосистемах, предполагаемая динамика:

Прочие выводы и предположения:

Приложения:

- карта - схема,

— фото и видеоматериалы (в электронном виде):

(перечень)

Ответственный исполнитель работ по учету численности животных:

Тел., эл. почта

(должность, Ф. И. О. полностью)

Подпись

Дата

Ответственный за выполнение и организацию учетных работ собирает у учетчиков подписанные ими заполненные ведомости (приложение А) и картосхемы с указанием на них масштаба, границ колоний, участков (выделов), учетных площадок (если выполнен не сплошной учет гнезд) и других перечисленных в них сведений. При недостатке места в карточке для дополнительной информации следует сделать приложение. Во избежание ошибок и для удобства при обработке карточек рекомендуется заполнять их отдельно на каждую стацию.

\section{Картирование информации}

Картирование является важным звеном в работе по подготовке к учету, его выполнению и при обработке учетных данных. Предпочтительно иметь контурную карту местности с нанесенной гидросетью и с точками ориентиров (населенные пункты и т.п.). Масштаб карт предпочтительно иметь с учетом размеров участков. Наиболее удобно работать с листами карт размером А4. 
Если учет баклана на интересующем участке выполняется впервые, то в обязательном порядке необходимо на карте нанести информацию о птицах на основании имеющихся служебных материалов и данных опроса работников природоохранных организаций, охотников, рыбаков и местного населения. Имея предварительные данные о местах гнездования, концентраций, кормовых участков и маршрутов перелетов, руководитель учетных работ может определить плановую потребность в трудозатратах, в транспортном и ином обеспечении.

Для единообразия предполагается использовать следующие условные обозначения на схемах.

A1, A2 и далее - колонии и малоразмерные поселения (стации размножения).

Б1, Б2 и далее - места коллективных ночевок и концентраций без гнезд (стации концентраций).

В1, В2 и далее - стации питания.

M1, M2 и далее - маршруты суточных перелетов между стациями.

\section{Подготовительные и полевые работы}

В зависимости от временных и исполнительских возможностей, метеорологических и технических условий, полевые учетные работы можно проводить в три этапа: в период между окончанием прилета и насиживанием, в период насиживания и выкармливания птенцов и после покидания гнезд всеми молодыми птицами.

В любом случае до начала полевых работ необходимо изучить материалы предыдущего учета (при его наличии) или результаты анкетирования и опросные сведения. Эту информацию необходимо нанести на карту. Знание учетчиком биологии и экологии баклана, а также особенностей пространственного размещения повышает производительность труда и достоверность учета. Применение фото-, видеорегистраторов и камер, беспилотных летательных аппаратов и быстроходных судов позволяет в короткие сроки и качественно выполнить учет.

Являясь ихтиофагом, баклан обитает только на водоемах или поблизости от них, и весь его жизненный цикл зависит о количества рыбы в водоеме и ее сезонных миграций и перемещений. При проведении учетных работ необходимо учитывать некоторые особенности экологии и биологии этого вида. Начало яйцекладки у баклана происходит обычно через 15-20 (до 30) дней после прилета. В кладке обычно 2-5 яиц. Насиживают самка и самец поочередно в течение 25-30 дней. При выкармливании птенцов на кормежку летают 3-5 раз в течение дня на расстояние до 20 км. Птенцы вылупляются голыми и беспомощными, с синим цветом кожи [12]. В первые дни жизни птенец баклана при отсутствии на гнезде родителя в течение 15 минут может погибнуть от перегрева на солнце (в жаркую погоду) или от переохлаждения в сырую и холодную погоду. Это происходит в том числе и в случае гибели одного из родителей, когда второй на длительное время улетает за кормом, или птиц вспугивают с гнезда.

Поскольку половозрелость баклана наступает в 3-летнем возрасте, то неполовозрелые птицы частично присутствуют в границах стации размножения (в колониях), держась преимущественно несколько обособленно. В то же время птицы этой возрастной группы и не имеющие пары (гнезда) в течение всего летнего периода обитают на стациях концентраций (места коллективных ночевок и отдыха). 
Г.Н. Янкус, М.Е. Овдин, А.А. Ананин. Организация учета большого баклана байкальской группировки

Визуально молодняк отличается «белобрюхостью». В гнездовой период наблюдается пространственная разобщенность неполовозрелых особей от гнездящихся вплоть до откочевки за пределы кормовых участков и мест концентраций гнездящихся бакланов. В период гнездования в местах концентраций и ночевок группировки вне колоний могут состоять преимущественно из неполовозрелых особей.

В зависимости от обилия рыбы в тех или иных водоемах бакланы совершают полеты на кормовые участки, как правило, по определенному маршруту (или маршрутам). Полезно знать маршруты полетов птиц гнездовых колоний, чтобы не включить их в перечень (в число) птиц, ночующих в других группах. При кормовых полетах бакланы чаще всего летят над водой на высоте $0,5-5$ м со скоростью 60-70 км/час. В поймах рек при наличии деревьев полет бывает на высоте 10-20 м и до 100 м при дальних перелетах.

На стации питания от мест ночевок бакланы вылетают после восхода солнца по определенным маршрутам. Знание таких маршрутов и стаций питания позволяет учетчику эффективно выполнить работу. При этом учет следует выполнять в точке, наименее удаленной от кормового участка. Возвращаются бакланы к местам ночевок до захода солнца теми же маршрутами, что и утром.

Стация концентраций в нашем случае не подразделяется на категории в целях упрощения полевых и камеральных работ, поскольку в любых случаях обеспечивает абиотические и биотические условия для бакланов в периоды дневного отдыха между кормежками и ночлегом (места коллективных ночевок и концентраций). Это скалистые участки берегов и островов, каменистые берега рек, берега, поросшие кустарником или ветвистыми деревьями. Такие места (участки) постоянно используют неполовозрелые особи в возрасте до трех лет и взрослые птицы, не имеющие гнезд.

\section{Литература}

1. Ананин А. А., Разуваев А.Е. Особенности популяционной динамики большого баклана (Phalacrocorax carbo L.) на северо-восточном побережье оз. Байкал // Разнообразие почв и биоты Северной и Центральной Азии: материалы III Всерос. науч. конф. (г. Улан-Удэ, 21-23 июня 2016 г.). Улан-Удэ: Изд-во БНЦ СО РАН, 2016. С. 27-31.

2. Ананин А. А., Овдин М.Е., Разуваев А.Е. Популяционная динамика большого баклана в Забайкальском национальном парке (Чивыркуйский залив, Средний Байкал) // Первый Всероссийский орнитологический конгресс: тез. докл. (г. Тверь, Россия, 29 января 4 февраля 2018 г.). Тверь, 2018. С. 6-7.

3. Ананин А. А., Овдин М.Е., Янкус Г. А. Динамика численности большого баклана на Северном Байкале // Современные проблемы орнитологии Сибири и Центральной Азии: матер. VI Междунар. орнитол. конф. Иркутск: ИНЦХТ, 2018. С. 17-21.

4. Бакка С.В., Киселева Н.Ю., Пестов М. В., Катунов Д.П. Организация сбора кадастровой информации о животном мире региона (на примере Нижегородской области) // Проблемы организации зоологических исследований в педвузах. Организация зоологических исследований: сб. ст. Саранск: Мордовский гос. пед. ин-т, 2001. С. 76-79.

5. Доржиев Ц. З. Новая экспансия большого баклана (Phalacrocorax carbo) в Байкальскую Сибирь // Сибирская орнитология. Улан-Удэ: Изд-во БГУ, 2006. Вып. 4. С. 242-244.

6. Овдин М.Е., Янкус Г. А., Ананин А. А. Большой баклан Phalacrocorax carbo на Северном Байкале // Байкальский зоологический журнал. 2017. № 2 (21). С. 75-78. 
7. Овдин М.Е., Янкус Г.А., Ананин А. А. Северобайкальская и баргузинская группировки большого баклана Phalacrocorax carbo в 2017 г. на Байкале // Байкальский зоологический журнал. 2018. № 2 (23). С. 57-60.

8. Пыжьянов С. В. Большой баклан снова на Байкале // Сибирская орнитология. УланУдэ: Изд-во БГУ, 2006. Вып. 4. С. 251-252.

9. Пыжьянов С. В., Пыжьянова М. С. Современное состояние большого баклана на Байкале и Хубсугуле (Монголия) // Изв. Иркутск. гос. ун-та. Сер. Биология. Экология. 2010. T. 3, № 1. С. 60-63.

10. Пыжьянова М. С., Пыжьянов С. В., Ананин А. А. Большой баклан в Центральной Азии: динамика ареала в XX-XXI веках // Экосистемы Центральной Азии в современных условиях социально-экономического развития: матер. междунар. конф. (г. Улан-Батор, Монголия, 8-11 сентября 2015 г.). Улан-Батор, 2015. Т. 1. С. 341-344.

11. Рябцев В. В. Большой баклан Phalacrocorax carbo вновь заселяет Байкал? // Рус. орнит. журн. 2006. Т. 15. Экспресс-выпуск 331. С. 900-902.

12.Рябицев В.К. Птицы Сибири: справочник-определитель: в 2 т. М.; Екатеринбург: Кабинетный ученый, 2018. Т. 1. С. 32. Т. 2. С. 13.

13. Спиридонов В. А., Зубакин В. А. Методика опросов охотников для получения данных о распространении редких видов животных и отношении к ним населения (на примере хищных птиц) // Направления и методы работы по программе «Фауна». Пущино, 1983. С. $45-48$.

14. Фефелов И.В., Анисимов Ю.А., Безруков А. В. Большой баклан Phalacrocorax carboновый гнездящийся вид дельты Селенги (озеро Байкал) // Рус. орнит. журн. 2016. Т. 25. Экспресс-выпуск 1233. С. 3-6.

15. Янкус Г.А., Овдин М.Е. Методика учета большого баклана байкальской популяции // Природные комплексы Северо-Восточного Прибайкалья: тр. Баргузин. гос. природ. биосфер. заповедника. Улан-Удэ: Изд-во БНЦ СО РАН, 2019. Вып. 11. С. 144-153.

\section{ORGANIZATION OF CENSURING THE BAIKAL GROUP OF GREAT CORMORANTS}

Yankus G. A., Ovdin M. E., Ananin A. A.

Gennady A. Yankus

Researcher,

Zapovednoe Podlemorye

71 Lenina St., Ust-Barguzin 671623, Russia

jankus@rambler.ru

Mihkail E. Ovdin

Director,

Zapovednoe Podlemorye

71 Lenina St., Ust-Barguzin 671623, Russia

znp.ovdin@mail.ru

Aleksandr A. Ananin

Dr. Sci. (Biol.), Deputy Director for Science, Zapovednoe Podlemorye

71 Lenina St., Ust-Barguzin 671623, Russia 
Г.Н. Янкус, М.Е. Овдин, А.А. Ананин. Организация учета большого баклана байкальской группировки

Chief Researcher, Institute for General and Experimental Biology SB RAS

6 Sakhyanovoy St., Ulan-Ude 670047, Russia

a_ananin@mail.ru

Abstract. The article presents a methodology for censuring birds, and their ecology for organizing long-term monitoring of the Baikal group of great cormorants. Censuring and analysis of distribution of the great cormorant begin by sociological surveys and questionnaires of the population in winter. Taking into account the collected information, we have developed a field research plan. With the arrival of birds we begin direct counts of nesting, feeding and resting individuals in certain areas of the Lake Baikal, accompanied by mapping. Priority is given to the biggest colonies. The use of photo-video recorders and cameras, unmanned aerial vehicles and high-speed boats allow us to quickly and efficiently perform censuring. The method was tested in 2013-2020 in the North-Eastern Baikal region, including the territory of Chivyrkuysky Bay (Zabaikalsky National Park), the Upper Angara River valley (with the Upper Angara Bay) and the north-eastern coast of Lake Baikal (Zabelin Barguzin State Natural Biosphere Reserve and Frolikhinsky Reserve).

Keywords: the great cormorant; censuring; Lake Baikal.

Статья поступила в редакцию 26.10.20; одобрена после рецензирования 17.11.20; принята к публикации 25.01.2021. 